\title{
Communicative Competence The Fifth Report of the Social and Emotional Compe- tence Test of Chinese Adolescents
}

\author{
Jingzhong Huang, Qian Wang, Huanchun Chen, \& Xingyuan Gao \\ East China Normal University, Shanghai 200241, Jiangsu, China
}

\begin{abstract}
$\mathrm{C}$
OMMUNICATIVE ability is embodied as "extroversion" in the Big Five Personality Test. Extroversion is an extremely important concept in personality psychology and a more common personality trait. Typically, it includes boldness, self-confidence, liveliness, enthusiasm, optimism, and being. In studying adolescents' social and emotional abilities, the OECD designed a communication competence evaluation framework based on "extroversion" in the "Big Five Personality" model based on the physical and mental development characteristics of 10-year-old and 15-year-old adolescents. In the OECD evaluation framework, there are three sub-dimensions of communicative competence: happy group, courage and vitality. This study is based on the evaluation data of Suzhou City in China and presents the evaluation results of the communicative ability dimension of the youth social and emotional ability survey in various ways. The data results are presented in the following three parts. The first part uses descriptive statistics to illustrate the overall score of communicative ability, the correlation coefficient of communicative ability and other sub-abilities, and the differences of each ability in age, gender, urban and rural areas, and school categories. The second part uses factors that affect the ability to communicate through multiple regression analysis, including background variables, student variables, teacher variables, school variables, family variables, and the impact of student happiness, courage and vitality. Finally, the third part uses multiple regression analysis of the 10-year-old and 15-year-old groups to determine the influence of happiness, courage and vitality on life outcome variables such as
\end{abstract}

(C) 2021 Insights Publisher. All rights reserved.

(c) (i) (2) Creative Commons Non Commercial CC BY-NC: This article is distributed under the (http://www.creativecommons.org/licenses/by-nc/4.0/) which permits non-commercial use, reproduction and distribution of the work without further permission provided the original work is attributed by the Insights Publisher. 
health and well-being. Research indicates:

\section{The Overall Status of Communication Skills}

From the average and standard deviation of the three sub-abilities of the students in the 10-year-old group and the 15-year-old group in Suzhou, the overall score of the students in Suzhou is higher than the world average. This indicates the depth of the development of the social and emotional abilities Suzhou's students. The high level also shows that the confidence of Suzhou students in themselves is higher than the international average. Moreover, compared with the international sample, the three sub-abilities of the Suzhou sample's communicative competence have correlate more among the three sub-competences: music group, courage and vitality. The music group and vitality show a significant middle correlation. Among the 10-year-old group of students, the correlation coefficient is 0.55 , and the correlation coefficient is 0.61 among the 15-year-old students. Although courage also relates to music and vitality, the correlation coefficients are all below 0.5 . There is a high degree of correlation between communication ability, emotion regulation, and collaboration ability.

In addition, there are significant differences in the ability to communicate among different ages, genders, urban and rural areas, and school types. The 10-year-old group and the 15-year-old group have a large gap in selfevaluation, while the gap in parental evaluation is relatively small, indicating that parents' evaluations of students in the three dimensions of happiness, courage and vitality tend to be more consistent, and there is a question as to whether parent evaluation can be considered student self-evaluation. The self-evaluation level of the 10-year-old students on their own happiness, courage and vitality is higher than that of the 15-year-old students. In the dimension of music group, girls in the 10-year-old group have significantly higher music group ability than boys. Students in the 15-year-old group show the opposite situation, with boys' music group ability significantly higher than that of girls. Regarding the courageous dimension, girls in the 10-yearold group are slightly more courageous than boys, and there is no obvious difference between boys and girls in the 15-year-old group. In terms of vitality, boys exceed girls in the 10-year-old and 15-year-old groups. The difference in performance between male and female students in the group is even greater at the age of 15 . Whether it is the 10-year-old group or the 15-yearold group, students in central urban schools can communicate much better than students in county and rural areas, but the difference between county and rural is insignificant.

\section{Influencing Factors of Communicative Ability}

Use multiple regression to analyze the factors that affect the ability of communication, including background variables, student variables, teacher variables, school variables, family variables, and the impact of students' happiness, courage and vitality. 
Regarding background variables, among the 10-year-old students, family possessions and family book collection significantly positively affect the three abilities of music group, courage and vitality $(\mathrm{p}<0.01)$, and the positive influence coefficients of family possessions are 0.40 and 0.36 , respectively. 0.46 , the positive influence coefficients of family collections are 0.07 , 0.06, and 0.07, respectively. Among 15-year-old students, gender, family possessions, family equipment and family book collection are key factors affecting students' happiness, courage and vitality ( $\mathrm{p}<0.01)$. Household possessions and household equipment significantly positively affect the communication ability of 15-year-old students. The positive impact coefficients of household possessions are $0.22,0.21$, and 0.34 . The positive impact coefficients of household equipment are $0.07,0.07$, and 0.02 , respectively.

Regarding student variables, whether in the 10-year-old group or the 15year-old group, the sense of security, friend relationship, good habit friends, and outdoor activity time all significantly and positively impact courage and vitality $(\mathrm{p}<0.01)$, while time spent on the Internet have a significant effect on the three items. Ability has a significant negative impact (except for the courage of the 10-year-old group, $\mathrm{p}=0.11$ ).

Regarding teacher variables, whether for the 10-year-old or 15-yearold students, the teacher-student relationship has a significant impact on their happiness, courage and vitality $(\mathrm{p}<0.01, \beta$ is around 0.10$)$. For the 10 -yearold students, the teacher's teaching age has a significant positive effect on music group and vitality, and the frequency of the teacher's social and emotional ability training has a significant positive effect on music group and courage $(p<0.01)$. In contrast, the 15 -year-old group's music group was not significantly affected by the teacher's teaching age $(\mathrm{P}=0.37)$, and courage was not significantly affected by the teacher's academic qualifications ( $p=$ $0.71)$. The music group, courage, and vitality were affected by the teacher, with an expected positive effect being more significant $(\mathrm{p}<0.01, \beta$ is 0.04 , $0.09,0.03$, respectively).

Regarding school variables, whether it is a 10-year-old group or a 15year-old group, the school's sense of belonging, school cooperation atmosphere and extracurricular activities all have a significant impact on their communication ability $(p<0.01)$. Of these, the school's sense of belonging has the highest degree of positive influence. The directional coefficient can reach about 0.50 . In creating a school atmosphere, the younger group is more suitable for cooperation, while the older group can appropriately encourage competition.

Regarding family variables, for the 10-year-old group of students, understanding fathers and mothers had a significant positive impact on students' happiness, courage and vitality $(\mathrm{p}<0.01)$, while understanding mothers had positive effects on the students' three abilities. The impact is greater ( $\beta$ is $0.08,0.04,0.06$, respectively). Punishment parents have different influences on students' communicative ability. The specific manifestation is that punishment mothers positively influence the three abilities of students, while punishment fathers have no significant influence. For students in the 15-year- 
old group, two different parenting styles and parents' high expectations have a significant positive impact on students' happiness, courage and vitality, while parent-child relationship problems have a significant negative impact $(\mathrm{p}<0.01)$.

\section{Communication Skills and Life Results}

From the perspective of academic performance, for the 10-year-old group of students, happiness, courage and vitality generally have a significant positive effect on the performance of China, mathematics and art (except for vitality for art, $\mathrm{p}=0.46$ ), and other $\mathrm{P}$ values are less than 0.01 . From the perspective of educational expectations variables, only courage significantly impacts educational expectations ( $\mathrm{p}<0.01, \beta=0.16$ ), indicating that more courageous students have higher expectations of their own learning performance. For 15year-old students, vitality has a significant positive impact on Chinese performance $(\mathrm{p}<0.01, \beta=0.14)$. Guogan significantly and positively impacts educational expectations ( $p<0.01, \beta=0.05$ ). From the perspective of mathematics and art achievements, the influence of communication skills is insignificant. From the perspective of global awareness among both 10-year-old and 15-year-old groups, the communicative abilities of group, courage and vitality all have a significant positive impact on global awareness $(\mathrm{p}<0.01)$. From the perspective of social relations, music group and vitality have a significant positive impact on students' social relations in both age groups ( $\mathrm{p}<$ 0.01 ). From the health point of view, vitality and music group have a significant positive impact on both groups, especially vitality, which has a greater degree of influence than music group; the correlation coefficient can reach 0.27 . From the perspective of quality of life, happiness, courage and vitality have a significant positive impact on the subjective well-being and life satisfaction of the 10-year-old students, and they have a significant negative impact on test anxiety $(\mathrm{p}<0.01, \beta=-0.10,-0.16,-0.53$, respectively). Lequn and vitality have a significant positive impact on the subjective well-being and life satisfaction of 15-year-old students, while courage and vitality have a significant negative impact on test anxiety $(\mathrm{p}<0.01, \beta=-0.08,-0.40$, respectively).

The results indicate that encouraging young people to develop good peer relationships plays an extremely important role in the formation and development of their happiness, courage and vitality. Both teachers and students must understand, trust, and respect each other, as well as form a basis of equal communication. A harmonious relationship between teachers and students is an important guarantee for promoting students' communication skills. To create a positive school atmosphere, a good school atmosphere is a key to improving students' communication skills. Parents should form a positive family education and create a democratic and harmonious family atmosphere to promote the development of happiness, courage and vitality. 
Source: Journal of East China Normal University (Education Science Edition), 2021, 39(9):93-108.

Correspondence to: Jingzhong Huang East China Normal University Shanghai 200241 China

Email: zjhuang@dedu.ecnu.edu.cn

Conflict of Interests: None.

Doi: 10.15354/bece.21.rp035 